\title{
African Economic Integration Development in Technological Transformation: Accessing the Importance of Ethical Leadership for Policy Implementation in SADC
}

\author{
Andrew Enaifoghe*1, Nomaswazi P. Dlamini ${ }^{2}$ \& Leonard U. Agwuna ${ }^{3}$ \\ ${ }^{1}$ University of Zululand, Faculty of Commerce, Administration and Law (CAL), South Africa \\ ${ }^{2}$ University of Zululand, Faculty of Arts and Humanities, KwaZulu-Natal, South Africa \\ ${ }^{3}$ University of Zululand, Faculty of Commerce, Administration and Law (CAL), South Africa \\ andyransey@gmail.com
}

\begin{abstract}
Most African states have suffered from severe macroeconomic disequilibria, foreign debt service burdens, and over-valued currencies. The lack of ethical leadership on policy implementation has led most Africa countries to linger highly behind in terms of development. Many countries are reliant on agriculture and yet suffer from high levels of unemployment and food insecurity on the continent. In these situations, it is logical for one to expect the full integration of Africa in terms of trade and migration, using the Southern African sub-regional integration as a case study. This study looks at the Southern African economic integration development and the importance of having ethical leadership for policy implementation. Qualitatively, this paper collected data and analysis them based on content, using secondary sources from different domains. The neo-Functionalist theory was applied and findings show that there is a failure to meet set targets in the SADC plan which has established a bad precedent for the sub-regions for African development, the failure is seen as lacking ethical leadership. It recommends that there is a need for African states to improve its infrastructure, recognise the capacity of the private sector to generate wealth and induce development, with open economies to member's states.
\end{abstract}

Keywords: Economic, development, ethical leadership, insecurity, integration, technologies, 4IR.

\section{Introduction}

The lack of ethical leadership on policy implementation has led most Africa countries to linger highly behind in terms of development. Many countries are reliant on agriculture and yet suffer from high levels of unemployment and food insecurity on the continent. In these situations, it is logical for one to expect the full integration of Africa in terms of trade and migration, using the Southern African sub-regional integration as a case study. This study looks at the Southern African economic integration development and the importance of having ethical leadership for policy implementation. Regional integration in Africa as a means of encouraging trade and securing economies of scale. One of the most prominent integration scholars like Ernst Haas (1961) defined integration as "the process whereby political actors in several distinct national settings are persuaded to shift their loyalties, expectations and political activities toward a new centre". Enaifoghe (2019), whose "institutions possess or demand jurisdiction over pre-existing national states, and the result of a process of political integration is a new political community, superimposed over the pre-existing ones". The United Nations Department of Economic and Social Affairs Division for Sustainable Development (2011), reports that the "World Summit on Sustainable Development" (WSSD) set a target in the year 2002.

For countries to take abrupt steps to development in the "formulation and elaboration of NSSDs and initiate their implementation by 2005", which was cutting-edge in a sequence of such calls. No doubt most countries are increasingly smearing the principles of "multi-stakeholder participation" and ownership, sound leadership and good administration of governance, ethics and value in all aspect of governance. Given the significant role of managing the development and "planning processes and ethical leadership" in providing the socio-economic support require to foster development through the integration of Africa, continentally. Integrating Africa continent into economic integration is seen to ultimately become the key to achieving higher economic development. Regional and economic integration is generally "when a group of countries get to develop a formal understanding or agreement through treaties, stating how they will conduct trade with each other" (Enaifoghe \& Asuelime, 2017), the idea is usually fostered to strengthen both economic and political relationships. Regional integration has "manifested itself historically in Africa, America and Europe as a bureaucratic effort to facilitate political unification and expansion of capitalism" (Chingono \& Nakana, 2008). This article looks at the importance of ethical leadership for policy implementation of the Southern African Sub-Regional Integration Development. 


\section{Methodology}

This study used content data analysis method, this method allows researchers to study, and thereby make sense of written documents, which may be available either in the public or private domain (Mogalakwe, 2006). The criteria for selecting documents in content analysis, or for focusing on particular literature, reflects the issues on which the researchers seek evidence.' Data were accessed through secondary sources, which then include the stuffing of internet sources, books, reports, periodicals, journal, and official documents on the African integration agenda integration policy implementation. Over 70 literature were sourced in the different domain including Google scholars and Scorpius on the subject and analysing them based on content and relevance.

\section{Literature Consideration}

The Position of SADC in African Regional Integration Polity: Despite the strength of the various arguments, virtually all regional integration efforts in sub-Saharan Africa, including the Southern Africa integration to date have failed to achieve their full objectives (Enaifoghe, 2019). The reasons for "the lack of success in the past and whether the current momentum for new regional initiatives" will address these problems are discussed in this study. In the perception of "African regionalism", the "Economic Commission for Africa (ECA) became the champion of regional (Enaifoghe, 2019). This paper contributes to the discourse on economic integration and African ethical development through regional growth and policy implementation, while exploring the lack of success and the challenges faced by the SADC integration in the Southern African sub-region and made recommendations for a way forward to achieving African regional development. The launch of "regional economic blocs not only strengthens member countries' positions on the global political landscape and bargaining power on international issues but also enables countries to collectively grapple with the region's economic progress" (Enaifoghe \& Adetiba, 2018). Khandelwal (2004), view regional integration in Africa as a means of encouraging trade and securing economies of scale. The discourses on the African regional economic integration development.

It is perhaps the earliest scholars of integration Balassa (1961), viewed "economic integration to be both a process and a State of affairs". As a State of affairs," it is the absence of various forms of discrimination between national economies" by removing or lowering every form of trade barriers, like tax and exercise duties. As a process, Balassa (1961), states that it includes the various "measures designed to abolish discrimination between economic units belonging to different nation-states, thus leading to the formation of a political union". In the above, therefore, following the end of colonialism in the Southern African subregion, Enaifoghe \& Adetiba (2018) underscores the significance that the SADC has undergone a comprehensive rearrangement with South Africa as the frontrunner, as opposed to its pre-1994 integration stance. They also added that "African regional cooperation has nevertheless been revitalised in several respects as a result of the two major events that began at the beginning of the 1990s" (Enaifoghe, Asuelime \& Adetiba, 2017). This includes the "abolition of the apartheid regime in South Africa and the subsequent stabilisation of political and economic relations in the sub-region of Southern Africa" (Enaifoghe \& Adetiba, 2018). In 2019, the African Union Organization reports that the renewed interest in regional integration as Africa's overall development strategy has led the majority of policymakers.

Enabled intellectuals to formulate a collection of plans and policies that will benefit most from enhanced cooperation in Africa (AU, 2019). More so, in concrete relations, "this strategic orientation has resulted in the proliferation of continental agreements and programs, such as the Abuja Treaty and the Agenda 2063" (Muzee \& Enaifoghe, 2019). However, the pan-African agenda of integration and regional efforts are lauded to have made momentous progress in the areas of trade, peace and security, air transport, the free movement of people and goods, and in emerging areas such as the environment and the climate through the various initiatives. According to the report compiled by the AU (2019), the momentous aforesaid developments, the successes in the African regional integration remains highly mixed given the anticipated outcomes and the enormous prospective of the continent. Its further states that; "Indeed, the African integration process remains subject to real obstacles relating to the quality of infrastructures, customs and administrative policies, the narrowness of the markets, the weakness of purchasing power, the poverty of capital markets, the lack of a diversified product base and the absence of mechanisms for coordinating and harmonizing regional policies." - AU (2019). The African Union report for 2019 outlined the fact that "fifty-five (55) years after the creation of the Organization of African Unity (OAU). Given the 
evolution of the international context characterized by new dynamics and mutations in the various regional groupings across the world - such as the exit of Great Britain from the European Union (Brexit) as well as the ongoing revisions of the North American Free Trade Agreement (NAFTA) - it is high time to reflect on the status of regional integration in Africa" (AU, 2019). In this regard, Muzee \& Enaifoghe, 2019), argued that the reverberations or impacts of the current globalization together with "a rise in nationalism also nurture concerns" in the most integrated regions outside the continent of Africa. Consequently, several expressions of opinions have risen to "interrogate the concept of integration in its, most recognized classical form" (Enaifoghe, 2019). The scholar states that this is given the "new world order focused on the globalisation of the economy that has so far been promoted by most countries of the world, especially in Europe, has finally given way to a desire to withdraw into oneself-Brexit" (Enaifoghe, 2019). In challenging this context, the idea of regional integration with organisational ethics and leadership and its approaches and significance, it would be advisable to reconsider African integration, to value its role, and then to reaffirm its African vision through the description of contextualised directions that can fuse and consolidate current progress.

This stops the dwindling effort of nationalism to the detriment of regional integration. Integration was to be "completed by the establishment of the African Economic Community (AEC) following a six-step, 34year, sequential strategy" (Enaifoghe, 2019). Enaifoghe, Adetiba \& Asuelime (2017), argued that "the labour division between the African Union Commission (AUC), the Regional Economic Communities (RECs) and the member states the implementation of the integration agendas as well as the rationalisation and progress of the RECs in a variable pace define the environment of African integration". Besides, this atmosphere stays complex, given the dissimilar interests of African integration actors as it is substantial to note that States are still reluctant to abandon their sovereignty (like D. R. Congo). According to Enaifoghe, Adetiba \& Asuelime, (2017), the consequence of such action has considerably hampered both the African regional integration process and that of the Southern Africa sub-regional, integration as a result of the insecurities that they might lose some level power of their national border. McCarthy (1995) noted that "the Lagos Plan was followed up in 1991 by the Abuja Treaty, re-affirming the commitment of the OAU's Heads of State to an integrated African economy". As argued by McLeod (2011), "regional integration has been credited with providing.

An important step towards a wider global involvement and has exhibited the potential to promote economic growth and reduce poverty through increased exports of domestic goods. It has been envisaged that integration has the potential to promote growth and reduce poverty through the increase of exports of domestic goods." Consequently, Matthews (2003) argued that "several regional groupings have long mushroomed in the post-war era across the globe, notably with the European Union (EU) and the Association of Southeast Asian Nations (ASEAN)." The existing African integration arrangements can be divided into two large groups. Those that were part of the Lagos Action Plan (LPA) adopted in April 1980, and those that were either in place or originated outside the LPA. The Lagos Plan has been promoted by the Economic Commission for Africa and launched in a special initiative by the Organisation of African Unity (Matthews, 2003). The African regional integration organisation envisaged having three regional arrangements that are aimed at creating separate but "convergent and over-arching integration arrangements" in the sub-Saharan sub-regions. The West Africa sub-region would function as the "Economic Community of West African States (ECOWAS)' that pre-dated the Lagos Plan". Furthermore, a Preferential Trade Area (PTA) that was established in 1981 consequently.

"Cover the countries of East and Southern Africa, which was eventually replaced in 1993 by the Common Market for Eastern and Southern Africa (COMESA)" (Enaifoghe \& Adetiba, 2018), and (Matthew, 2003). The third regional arrangement is the "Central Africa the treaty of the Economic Community of Central African States (ECCAS)" that was approved in 1983, yet to be fully ratified. The last but not the least is arrangement of the Arab Maghreb Union (AMU) propelled in North Africa, these arrangements were expected to lead to an all-African common market by the year 2025. In Africa, several regional groups have emerged over the recent time, explicitly, "the Economic Community of West African States (ECOWAS). The East African Community (EAC), the Common Market for East and Southern Africa (COMESA), as well as the 'Southern African Development Community' (SADC)", which is the focus of this paper. African Heads of State met at Sirte and launched the African Union to replace the Organisation of African Unity (OAU) with the African Union (AU) in April 2001. Since the first arrangement by the African regional integration, the second group of integration engagements has developed outside the Lagos Plan of Action (LPA). Matthews (2003) point out that some "countries in this region are also joined with countries in the Horn of Africa in the Intergovernmental Authority on Development (IGAD). 
Despite the multiplicity of groupings, SSA regional groupings have not been very effective". Among the reasons for this could be cited to be the following: "intra-regional trade in Africa as a share of total foreign trade has traditionally been low compared to other regions. Figures in the early 1990s suggest that the proportion was only 8.4 per cent in 1993 compared with Western Europe (69.9 per cent), Asia (49.7 per cent), North America (33 per cent) and Latin America (19.4 per cent) (WTO source, quoted in McCarthy, 1995). However, recorded trade underestimates the volume of actual trade and, if a proper account was taken of the size of informal trade, the African numbers would not look so out of line. Furthermore, there is evidence that the importance of intra-regional trade has been steadily increasing in recent years" FAO (2002). Matthews (2003) argued that Most African countries may have experienced significant macroeconomic imbalances, foreign debt service pressures, overvalued "currencies, lack of trade finance, and a narrow tax base, with customs duties a major source of revenue. Protecting import substitution techniques implemented by a variety of countries since their independence" has resulted in a host of protocols hampering "trade such as licensing, administrative foreign exchange allocation, special taxes for acquiring foreign exchange", and the advance import deposits among other components.

Consequently, the socio-economic context in Africa generally has been unfavourable to the development of the regional commitments likewise in the Southern Africa sub-region. This was confirmed by Asante (1997: 17), who said that "the design of African integration schemes around inward-looking industrialization meant that the economic costs of participation for member states are often immediate and concrete. In the form of lower tariff revenues and greater import competition", while the economic welfare profits are said to be long-term and further uncertain and further often unevenly disseminated among member states. In the Southern African sub-region with it inception of the SADC organisation has been guided by a desire to form a "regional integration bloc that will link regional economies, then strengthen the region's economic performance, and enhance the region's political stability" (SADC, 2012). The organisation was initially established in the year 1980 as the "Southern African Coordination Conference" (SADCC) (Takirambudde, 1999), the party aimed not only to "reduce economic dependency on the then apartheid South Africa" (Hancock, 2010). To forge economic ties to establish genuine and egalitarian regional integration through the mobilisation of capital for the promotion of interstate and regional policies (Ahmed, 2008).

Following the political independence of some of the Southern African Member States, the region agreed to "revise the mandate of the regional body by concentrating more on economic and political problems in the post-colonial era" (Draper \& Kalaba, 2006). The creation of the SADC in 1992 was therefore seen as a continuation of efforts to improve collective self-reliance in the Southern African region" (Enaifoghe, Asuelime \& Adetiba, 2017). On the other hand, there can be no economic growth without political stability. Thus the current revamped regional body has integrated policy concerns within its main mandate. Mutisi (2016), claims that "political rather than economic considerations set in motion the process of regionalization in Southern Africa". Enaifoghe (2019), articulated that the "regional body recognised that economic growth can only be achieved by concerted effort; thus the Member States saw regional integration as a gateway to economic development within the region". While the search for "the SADC regional bloc to achieve these goals has resulted in overambitious programmes and estimates being placed in place" (Mutisi, 2016; Enaifoghe, 2019). The SADC Treaty, therefore, put the SADC bloc at the centre of efforts to achieve regional economic integration, independence and social justice for the people of Southern Africa.

The commonalities, according to Chauvin \& Gaulier (2002), inform "the search of the region for, collective peace and sustainable growth, both of which can be accomplished by economic regional integration." Bhagwati (2008), articulated that the SADC's operations "towards regional integration have been marked by the presentation of overambitious programmes", despite the apparent cracks "within the regional grouping". The SADC's guiding principles were to minimise economic dependency initially "on apartheid South Africa, but later on other economies outside the SADC region" (Enaifoghe \& Adetiba, 2018). The member states have envisaged the building of economic ties as a means of achieving genuine and inclusive regional integration. However, the leaders appear to lack the ethical leadership to accomplish this goal. The quest to develop economic relations motivated the desire to mobilise capital to promote and enforce "governmental, inter-state and regional policies" in the SADC sub-region. In addition to these visions, the SADC Member States have committed themselves to "collaboration" to ensure international cooperation. This is so that it can challenge and know the way forward in understanding and developing African ethical reflections. 
Influence of the Global-View on Africa Organisational Ethical Development: Most Africa society has been confronted with historic challenges since the establishment of the new millennium. This needs the "visions of the future so attractive, inspiring and compelling that people will shift from their current mindset of focussing on managing crises" to predicting the future (Kandula, 2008). Looking at the peripheral challenges and the transformations that are currently happening in various "organizations' environment", it is crucial that Africa leaders invoke a survival strategy, so that the future could be well catered for. Keeping this in mind, it is envisioned by Hammel \& Prahlad (1994), that the "future position of organizational ethics and leadership is found in the intersection of changes in technology, lifestyle, regulation, demographics and geopolitics". With new developments that are emerging in the global politics and the economy, the main players are shifting (Gupta, 1994), besides, history has shown that the process of transformation is inherent in the development of mankind. Over and over again (Kher, 1997), looking at the ever-developing technology and globalisation in the world today. Combined with rapid obsolescence, the anticipation of more value-added organisational "ethics and leadership in Africa" is nonetheless overwhelming (Mathooko, 2013).

Also with the "new generation and the band of young leaders. Africa has been seen as a continent of complexities, with a large range of climate, topography, history, peoples and languages" (Enaifoghe, 2019). This complexity is likewise "compounded" by ethnical division, tribal wars, self-interest and corrupt leadership, the disparity in wealth, organized corruption and the enormous unemployment rate in the continent. The need for a comprehensive understanding of "the diverse landscape" of Africa required if its assessment in leadership and structural or the organizational ethics must be thoroughly discussed and recognised (Mathooko (2013). The developing leadership styles with its organizational leadership ethics in Africa have been prejudiced by the influence of western culture and ideologies that define the lives of Africans in Africa, in relation to their existence and relationship with each other. The "leadership styles and organizational ethics" (Mathooko, 2013), in Africa, are also swayed by the obvious resources that are available and their management by a few individuals. Despite the fact prudently acclimatizing to the external "forces of whose ethics" and ideologies fail to resolve "the leadership problems of corruption" in Africa.

The above is to simply state that Africans often tend to copy their leadership, moral practices and reflections from a background that does not apply to them, just because they have intermingled in this environment for many years. The foreign environment is composed of a "complex whole, with a just interrelationship vis-à-vis social relations" and environmental events in a nutshell (Mathooko, 2013). Discussing leadership style in Africa context, the organizational ethics is said to revolve around certain principles either "written and/or unwritten, the ethical values, ideologies, rules, principles and standards, that may be pinched from the harmonious or peaceful coexistence with the biosphere" (Mathooko, 2013). Subsequently, how these fundamentals are applied to human social realities is dictated by the method of leadership and the ethical rationale of the leaders. Generally, Africa has a broad array of "complexities which are compounded" by ethnicity, wealth and social inequalities, and the high level of unemployment among others. However, to understand and attempt to address the current problem associated with Africa leadership and organizational ethics, there is need for a broad grasp of the complex landscape in Africa, through a three-dimensional unscrambling of the existence of its people. African global ethics (Afroglobal ethics) has advanced over a period which unifies its "organizations and leadership.

Since it is defined to form part of human social life and practices", subconsciously or "unconsciously by the people, while transforming from one activity to another through intergenerational changes (Mathooko, 2013). In the global world today, chances are fast transforming the social environment with science and technological advancement, globalization, and liberalization in which organizations function. In such a setting, it is expected that a true leader to be flexible and not rigid, having the ability to use diverse leadership styles as the situation requires it and makes an effective leader. Having said that, only leaders with the realistic outlook live to stimulate lives, they can live with a true cause that they are willing to defend and embrace organizational ethics and followed by a leadership style that will stand. The leadership and organizational ethics are still in its infancy stage in Africa, despite being the cradle of human existence, and even with its "new generation of young leaders" today. The potential stance of corporate ethics and leadership trends in Africa needs to be unravelled in the light of recent developments in "technology, demographics, lifestyle and geopolitics" drifts evolving in the global economy and polity. The way globalization is taking the world by storm right now, we do not think there is any country that can afford to ignore it, as interdependence has become the standard norm of a new society. 
The understanding African view of organizational ethics also revolves around systems that is ethical. Strategic procedures, ethical values, moralities, rules and benchmarks, that ultimately drawn from the peaceful coexistence with the environment. Developing African view of organizational ethics in the global system developments in the development, defence and security of human life, including the conservation of human honour, the protection of the dignity of all human beings and the protection of nature and multiplicity, with a dedication to "guiding social and moral behaviour. These principles are enshrined in the Universal Declaration on Bioethics and Human Rights" (UNESCO, 2005). The viewpoints and attitudes of the African civilization that touch on ethical behaviour, according to Mathooko (2013), no systematic exploration and explanation have yet been given and thus there is a real need for a comprehensive and extensive study and interpretation. He further points out that to do this, the three-dimensional (3D: history, present and future) scope of governance and organisational ethics must be unravelled and interpreted holistically through the contextualization of the international ethical normative instruments.

\section{Organizational Ethical Leadership in Erratic Eras and Technological Transformation}

The functioning setting of organizations is transforming itself very quickly in Africa, occasioning the scarcity of true and outstanding leadership. However, in the face of the diverse developing concerns of ethical flora such as perversion, ethnicity, corruption and Xenophobia/Afrophobia, among others, it is imperative for Africa to institutes the idea of "checks and balances in governance". The current advancement of "globalization, liberalization, climate, science and technological changes and progress it forced on organizations", is to redefine their arrangements, methods, and developments (Kandula, 2008), have undoubtedly influenced the leadership for organizational ethics. The contemporary world of today has become interdependently integrated like never before as a global community, thereby making globalization to be one of the most prevailing and pervasive influences on the working environment, communities, and people's social lives (Mathooko, 2013). Globalization, as it is today, seems to be irrevocably ongoing to counter the prevailing local, regional, national, legal and, seemingly, cultural boundaries that have been blocking the material, ideological, and social transformation (Bina, 1997). That built a complex society with a series of new prospects and ensuing problems of widening social inequalities, this however candidly applies.

When one deliberates on the availability of health services and types of machinery with regards to technologies. Besides, numerous other concerns exist in Africa which raises the concern for deep ethical fear and prominence for the global community that is diverse within various cultures as a result of globalisation. Many countries, including Africa, have liberalised their economies in the form of trade deregulation and tariff cuts to improve the productivity of their economies. The liberalisation of economies has "strong effect on health services, particularly where cheap or fake drugs and equipment are readily available to patients and local medical practitioners" (Enaifoghe, 2019). Therefore, if strict regulations are not in place, the ethical stature will become questionable and examined. Due to the increasing globalization, the world is confronted with a high level of turnover in terms of technologies that are related to "health/medicine and other disciplines". Not forgetting the fourth industrial revolution (4IR). Countries are further observing a "compression of the time scale on which new technology" is implemented within a limited period between discovery and implementation (Keyes, 1995; Mathooko, 2013). And the speed of innovation is extremely high. This rapidity of technological change, according to Mathooko (2013), continues to "challenge all organisational strategies and affects all human lives".

The accessibility of capability such as "telemedicine is limited in developing countries" as a result of low per capita income and technical appreciation and advancement. Technological change and transformation are "sine qua non not only for the survival of an organization" but also for the preservation of its "ethics, competitive edge" and development (Kandula, 2008). The economic situations in most countries particularly in Africa. Usually constrain individuals to reflect or reason inversely, which is established on the amount of the predicament and their present positions. The ethical thoughts could be directed positively or negatively in such an environment, towards justifications of such experiences (Mathooko, 2013). The paradigm of ethical progress accentuates on the: intensification of "good and the creation of greatest good for the greatest number, while at the same time embracing peace, good health, abundance and progress in all their forms" (Enaifoghe, 2019). Based on the "African community structure, it should also be understood that African ethics is weighed on duty and not on rights, thus placing a great deal of emphasis on human welfare" (Mathooko, 2013). It is required of every individual to show "concern for the interests of others" as a moral duty, stemming to "African morality duties" undermining rights, and not contrary. 
The ethical understanding is being defied by the insight of peoples' rights and the advent of the universal, human rights sets. Another impact "on leadership and organizational ethics in African governance is supererogation, which is an act beyond the call of duty, an act over and above what a person is required to do as a moral agent" (Mathooko, 2013). This suggests that the moral sensitivities of Africans ought to be extended to all people, notwithstanding of who they are, where they are from, their race, colour, their cultures or even the societies they came from - humankind. The same ideal ethical value should be extended and practised at all sphere of government, instead of playing ethnic politics. Neo-functionalism theory originated sometime in the mid-1950s, according to Enaifoghe \& Adetiba (2018), the "theory of regional integration is a mechanism by which countries eliminate barriers to free trade.

Theoretical Explanation of Afroglobal for Neo-Functionalist Approach: This section gives a conceptual explanation of how the theory of Neo-functionalism can be applied in the context of Southern Africa, and how it should be extended to African regional integration, and how can it help improve the current state of the continent's development. Though it is a European theory. However, thinking Afroglobally is believed to help Africa to develop its regional development if applied ethically and politically correct. The neo-functionalist theory, Enaifoghe \& Adetiba (2018), states that at "the centre of international relations is the nation-state and because nations have been affected by many transnational phenomena, there is the need for state actors, political scientists as well as a humanist". To "formulate the means to smoothen relationship among nations while helping to establish a long-lasting peace" (Enaifoghe, 2019). The theory of regional integration was "the brainchild of the functionalists" (Enaifoghe \& Adetiba, 2018). The functionalist approach according to B Behr (2010), articulated that revise "nations maximize their [economic and political] interest owing to the assistance of international organizations based on functional rather than territorial principles". In this study, therefore, from the functionalist's approach, the theory can be "explained from two perspectives; political and economic" points of view that fall within the scope of this paper.

Enaifoghe \& Adetiba (2018), claims, however, that regional integration actually cannot happen if the countries concerned are not physically interconnected. Neo-functionalism has helped explain Western Europe's integration theory". The theory is closely related to the methods of unification of the founding fathers. Jean Monnet's method of integration was intended for specific sectors in the expectation that spillover effects can be realised to further the progress of integration, but early neo-functional measures have also been found. Schmitter (2005) argues that the procedures of Jean Monnet for a mutual appreciation and 'piecemeal issues' solving is embedded like neo-functionalism'. While Rosamond stated that "Neo-functionalism can be read at one level as a theory provoked entirely by the interactive activity among the original six member states" (2000). Further down, Eilstrup-Sangiovanni (2006) argues that the "neo-functionalism is the result of a behavioural change in American social science", which also focuses on structural forms, actions and integration processes (2006). However, "at the time of the 'empty chair' crisis, the neo-functionalism theory appeared too incapable of describing the direction of integration in general because of its extreme Eurocentric existence" (Enaifoghe \& Adetiba, 2018). The consequence of the integration process is in the opinion of the functionalists, where a separate institutional entity executes its tasks as its effects. Whereas for the neo-functionalist, everything is moved to a new core as a result of the "new political culture" that emerges (Haas, 1958).

Jean Monnet saw "increased European integration as the most important originator of a stable Europe. In the course of the centre, the importance of nationalism and the national state" to neo-functionalism would decrease supranational sate. Noting the fact that there are three instruments that neofunctionalists projected, it is a driving force of integration process which are very fundamental as positive spillover, "transfer of domestic alliances", technocratic automaticity. Furthermore, the Neo-functionalism theory has Positive spillover on integration, According to Wallace (2004) "positive spillover" is when "the sector such as coal and steel governed by the central institutions creates pressure so that the neighbouring areas of policy such as taxation and wages are influenced by integration". The model of spillover is described as "the process of generating new political goals" (Cini, 2004). The effect of neofunctionalism theory, it can transfer domestic alliances. Applying the theory, in the process of integration the different national interest groups, associations and elites will shift their loyalty away from national institutions toward the supranational European institution. And this can be experienced in African regional integration as well. The simple explanation to this is that at the national level, the various group will acknowledge the new "institution as a better instrument by which they can achieve a better result in their interests rather than through national institutions" (Enaifoghe \& Adetiba, 2018). 
According to Cini (2004), this will lead to "an establishment of elite groups holding pan-European ideas and norms and they will try to persuade national elites to turn their loyalties to the supranational" cooperation. The power of neo-functionalism theory on socio-economic development, according to Enaifoghe \& Adetiba (2018), is believing that the development of the neo-functionalism theory can automatically lead to the emergence of 'dramatic political actors' also, changes in international systems may affect the regional cooperation". The scholar like Cini (2004), believes that the concepts of the spillover can also develop further to 'spill-around' and 'spill-back'. Nevertheless, neo-functionalism revealed the logic of the development of Europe in the post-war uniting. The theory is still very useful in theorizing although very limited in its capability (Haas, 1958). Schmitter (2004), argues that neo-functionalism "provides building blocks for structures and that it is useful for reformulation", and further points out that this could be due to the propensity towards self-criticization of its actors. The scholar also argues that the theory affects amplification and broadening as it contributes to conflicts, inconsistencies and demands that can be overcome by advance integration (2004).

In the African sense, as the centre of neo-functionalism is the use of the idea of 'spill-over,' the mechanism poses situations when governments take an initial decision to position "certain sector under the authority of central institutions, which generates pressure to expand the authority of institutions to neighbouring policy areas such as currency exchange rates, taxation and wages". This fundamental claim meant that regional integration in Africa would become self-sustaining, and as a result. 'Spill-Over' would cause the economic and political dynamics of further cooperation. The theory foresaw the Logic of Diversity, which 'sets limits to the degree at which the 'spill-over' mechanism can restrict the freedom of action of governments. The logic of diversity means that losses on critical issues are not compensated for by gains on other issues. Integration, guided by national governments, is often thought to be focused on "domestic political and economic issues of the day" and thus the theory denies the idea of spillover effect that Neofunctionalism implies. It opposes the notion that supranational entities are at the same degree (in terms of political influence) as national governments.

\section{Conclusion and Recommendations}

This article highlighted the ethical leadership needed to promote African regional integration through the sub-regional implementation of policies. As Africa has the potential to develop its continent looking at its fastest rate of demographic growth in the world. The call for African Development and good governance strategies for both regional and continental development is truly paramount in the 21st century as stated above. Looked at African development challenges concerning the various calls and the target set by a different international organisation on the African development process. While most countries are increasingly smearing the principles of "multi-stakeholder participation and ownership, sound leadership and good administration of governance, ethics and value in all aspect of governance, the accountability for states planning and finance have subsequently played key roles in the NSSD course of development. Africa should create strategic development planning processes that will provide.

The socio-economic support requires to foster development in the continent through the integration of Africa continentally. This article contributes to the discourse on African ethical values in governance and regional development, while it unpacked some of the challenges faced by the SADC sub-regional integration, due to lack insecurities among member states to let go of some their sovereignty to integrate and the moral values to human ethics. The polity of Southern African integration arrangement in the subregion is seen to be the "ideal for regional economic integration" given the fact that it is characterised by many countries with similar "small or poor economies" except South Africa. As a way for Policy Recommendation, an asymmetric integration would lead to de-industrialisation, thus locking less developed economy into structural stagnation. Further, SADC needs to develop mechanisms to deal with the security challenges it faces, as there is a link between security and development.

\section{References}

African Union (AU). (2019). Report on the Status of Regional Integration in Africa. The 3rd Specialized Technical Committee on Finance, Monetary Affairs, Economic Planning and Integration Experts Meeting 4-6 March 2019, Yaoundé, Cameroon.

Ahmed, A. K. (2008). An analysis of the regional integration in Sothern Africa: A South African perspective (2008) Tralac, 12. 
All-Africa.com. (2010). Southern Africa: Leaders of SADC postpone launch of Customs Union. Available at http://allafrica.com/stories/201008180923.html. Accessed 12 May 2019).

Asante, S. K. B. (1997). Regionalisation and Africa's Development: Expectations, Reality and Challenges. London: Macmillan, 22(3), 331-347.

Balassa, B. (1961). The Theory of Economic Integration. London. George Allen and Unwin.

Behr, H. (2010). A History of International Political Theory: Ontologies of the International. Houndmills: Palgrave Macmillan.

Bhagwati, J. (2008). Termites in the trading system: How preferential agreements undermine free trade (2008) at 43.

Bina, C. (1997). Imperatives and development tendencies. The political economy of globalization, 41-58.

Chauvin, S. \& Gaulier, G. (2002). Regional trade integration in Southern Africa. CEPII, (2002) 23.

Chingono, M. \& Nakana, S. (2008). The challenges of regional integration in Southern Africa, African Journal of Political Science and International Relations, 10(3), 396-408.

Cini, M. \& Perez-Solorzano, B. N. (eds.) (2004). European Union Politics. Oxford: Oxford University Press.

Draper, P. \& Kalaba, M. (2006). South African international trade diplomacy: Implications for regional integration, (2006) 37.

Economic Commission for Africa. (2017). Assessing Regional Integration in Africa Viii. Bringing The Continental Free Trade Area About. Printed in Addis Ababa by the ECA Printing and Publishing Unit. ISO 14001:2004 certified.

Eilstrup-Sangiovanni, M. (ed.) (2006). Debates on European Integration. Hampshire: Palgrave Macmillan Ltd.

Enaifoghe, A. O. \& Adetiba, T. C. (2018). South African Economic Development and the SADC Subregional Integration, Journal of Economics and Behavioural Studies (JEBS), 10(1), 135-145.

Enaifoghe, A. O. \& Raquel, A. (2018). South Africa's National Development vis-à-vis Regional Dynamics. Journal of African Foreign Affairs (JoAFA), 5(1), 129-147.

Enaifoghe, A. O. (2019). South Africa's Politics of Regional Integration in SADC and its Socio-Economic Implications. Journal of African Foreign Affairs (JoAFA), 6(1).

Enaifoghe, A. O., Asuelime, L. E. \& Adetiba, T. C. (2017). South Africa's Management and Investments in SADC: A Strategy for the Implementation of its National Development (Masters Dissertation).

Ernst, H. (1961). International Integration: The European and the universal process, (15), 366.

FAO. (2002). Developing country experience with the implementation of the Uruguay Round Agreement on Agriculture: Synthesis of the findings of 23 case studies, Paper No. 3, FAO Geneva Symposium on the Experience with Implementing the WTO Agreement on Agriculture and Special and Differential Treatment to Enable Developing Countries to Effectively Take Account of their Development Needs, Including Food Security and Rural Development, Geneva, 2 October 2002.

Gupta, K. R. (1994). GATT Accord and India. 1994, New Delhi, Atlantic Publishersis:ep:

Hammel, G. \& Prahlad, C. K. (1994). Competing for the future. 1994, Boston, Massachusetts, Harvard Business School Press.

Hancock, K. J. (2010). What role for the EU in the Southern African Customs Union (SACU): Advocate, cajoler, or bully? A paper prepared for the Conference on the Diffusion of Regional Integration, Kellog-Forschergruppe, Transformative Power of Europe, Berlin (10 - 11 December 2010) at 5.

Kandula, S. R. (2008). Strategic Human Resource Development. 2008, Prentice-Hall, India

Keyes, J. (1995). Technology and Change. Technology Trend lines. Edited by: Keyes K. 1995, New York: Van Nostrand Reinhold.

Khandelwal, P. (2004). COMESA and SADC: Prospects and challenges for regional trade integration, IMF Working Paper (2004).

Kher, M. (1997). Coping with technological change. 1997, New Delhi, Sage

Mathooko, J. M. (2013). Leadership and organizational ethics: three-dimensional African perspectives. BMC Medical Ethics, 14(2).

Matthews, A. (2003). Regional Integration and Food Security in Developing Countries. Food and Agriculture Organization of the United Nations Rome, 2003

McCarthy, C. (1995). Regional integration: part of the solution or part of the problem? In Ellis, S. ed., Africa Now: People, Policies, and Institutions. London, James Currey/Portsmouth, Heinemann.

McLeod, H. (2011). Regional integration and the role of donors, Yearbook Monitoring Regional Integration in Southern Africa, 17.

Mogalakwe, M. (2006). Research Report. The Use of Documentary Research Methods in Social Research. African Sociological Review, 10(1), 221-230.

Mutisi, M. (2016). SADC Interventions in the Democratic Republic of the Congo. ACCORD (African Centre for Constructive Resolution of Disputes) 19 OCT 2016 
Muzee, H. \& Enaifoghe, A. O. (2019). Towards an Inclusive Model of African Regional Integration: How effective has the Linear Model been so far? Journal of Economics and Behavioral Studies (JEBS), 11(1).

Rosamond, B. (2000). Theories of European Integration. Hampshire: Palgrave Macmillan Ltd.

SADC. (2012). Regional Vulnerability Assessment \& Analysis Programme (Rvaa). SADC Treaty. Art 5 (1) (a) and (b), SADC Treaty, Art 5 (1) (a), (b), (g) and (I), SADC Treaty and Art 5 (1) (a) and (b), SADC Treaty.

Schmitter, P. C. (2005). Ernst B. Haas and the Legacy of Neofunctionalism. Journal of European Public Policy, 12(2), 255-272.

Takirambudde, P. N. (1999). The Position of SADCC in the international division of labour and prospects for regional cooperation, PULA: Botswana Journal of African Studies, 7(1), 97-116.

UNESCO. (2005). Universal Declaration on Bioethics and Human Rights. 2005, UNESCO Paris

United Nations Department of Economic and Social Affairs Division for Sustainable Development. (2011). Sustainable Development in the 21st century (SD21) Review of implementation of Agenda 21 and the Rio Principles. December 2011, DRAFT

Wallace, H., Pollack, M. \& Young, A. R. (eds.) (2005). Policy-Making in the European Union. Oxford: Oxford University Press. 